\title{
Uso da terra na Área de Preservação Permanente do rio Paraíba do Sul no trecho entre Pinheiral e Barra do Piraí, RJ
}

\author{
Stephanie Freitas Couto de Magalhães \\ Samara Salamene \\ Tom Adnet Moura \\ Viviane Costa Elias \\ Márcio Rocha Francelino \\ Universidade Federal Rural do Rio de Janeiro - UFRRJ \\ BR 465, km 7, Instituto de Florestas, 23890-000, Seropédica - RJ, Brasil \\ stephanie.magalhaes@hotmail.com; salamene@yahoo.com.br
}

\begin{abstract}
This study aimed to evaluate the land use in APP of Paraíba do Sul River, the stretch of $13 \mathrm{~km}$ between Pinheiral and Barra do Piraí municipalities, RJ, comparing the current occupation of this area with current legislation. For land use mapping satellite images provided by Google Earth 5.0 were used. The images were grouped in mosaic and georeferenced. The river was traced in shapefile format, and its APP generated through a buffer in ArcGIS 9.2. According to brazilian Forest Code, river APP's with the dimensions of the Paraiba do Sul must have a width of $100 \mathrm{~m}$. However, it was found in study area only $40 \%$ of forest, and most of the APP covered by pasture (54\%). The presence of vegetation in APP is very important for the sustainability of water courses. Despite the Paraíba do Sul had not provided the forest cover across the APP, the values were higher when compared to similar studies in other areas.
\end{abstract}

Palavras-chave: remote sensing, image processing, riparian forest, sensoriamento remoto, processamento de imagens, matas ciliares.

\section{Introdução}

As matas ciliares são vegetações que ocupam as margens de cursos d'água e são de extrema importância para a manutenção dos mesmos, pois: auxiliam na infiltração de água no solo, facilitando o abastecimento do lençol freático; mantêm a qualidade da água, dificultando o escoamento superficial de partículas e sedimentos que causam poluição e assoreiam os recursos hídricos; fornecem sombra, mantendo a estabilidade térmica da água; impedem o impacto direto da chuva no solo, minimizando processos erosivos; servem de abrigo e alimento para grande parte da fauna aquática (Lima e Zakia, 2004).

Apesar de protegidas por lei federal através da criação das Áreas de Preservação Permanente (Brasil, 1965), as matas ciliares se encontram devastadas no Brasil, principalmente devido ao processo de urbanização desordenada e práticas agrícolas intensivas (Martins, 2001). Isso traz danos não só ambientais e ecológicos, mas também econômicos para o país, pois os recursos hídricos, além do abastecimento de água, são utilizados na geração de energia elétrica (Salvador, 1986).

O rio Paraíba do Sul, que abrange os estados de São Paulo e Rio de Janeiro, apresenta importância cultural, social e econômica para a Região Sudeste do nosso país (Couto, 1998), fazendo-se, assim, necessária a manutenção das suas condições ambientais. No estado do Rio de Janeiro, grande parte do abastecimento de água provém desse rio. A região metropolitana fluminense, por exemplo, que possui cerca de 11 milhões de habitantes, é abastecida pelo rio Guandu, cujo dois terços do volume de água é oriundo o rio Paraíba do Sul, através de uma transposição que ocorre no município de Barra do Piraí (INEA, 2009).

Tendo em vista sua importância, este estudo realizou um levantamento do uso da terra na Área de Preservação Permanente do rio Paraíba do Sul, no trecho entre os municípios de Pinheiral e Barra do Piraí, no estado do Rio de Janeiro. Os resultados obtidos poderão auxiliar no planejamento para ocupação e restauração de áreas na região. 


\section{Material e Métodos}

\section{1 Área de estudo}

Compreendeu a Área de Preservação Permanente (APP) no trecho do rio Paraíba do Sul que divide os municípios de Barra do Piraí e Pinheiral, estado do Rio de Janeiro (Figura 1). O rio Paraíba do Sul nasce na confluência dos rios Paraitinga e Paraibuna, estado de São Paulo, e tem uma extensão total de cerca de $1.120 \mathrm{~km}$.

O Código Florestal brasileiro (Brasil, 1965) determina que cursos d'água com 50 a 200 metros de largura possua uma APP com 100 metros de extensão a partir da margem. O rio Paraíba do Sul apresenta no trecho estudado aproximadamente $13 \mathrm{~km}$ de extensão e 90 metros de largura, logo sua APP será de $100 \mathrm{~m}$ de acordo com a legislação.

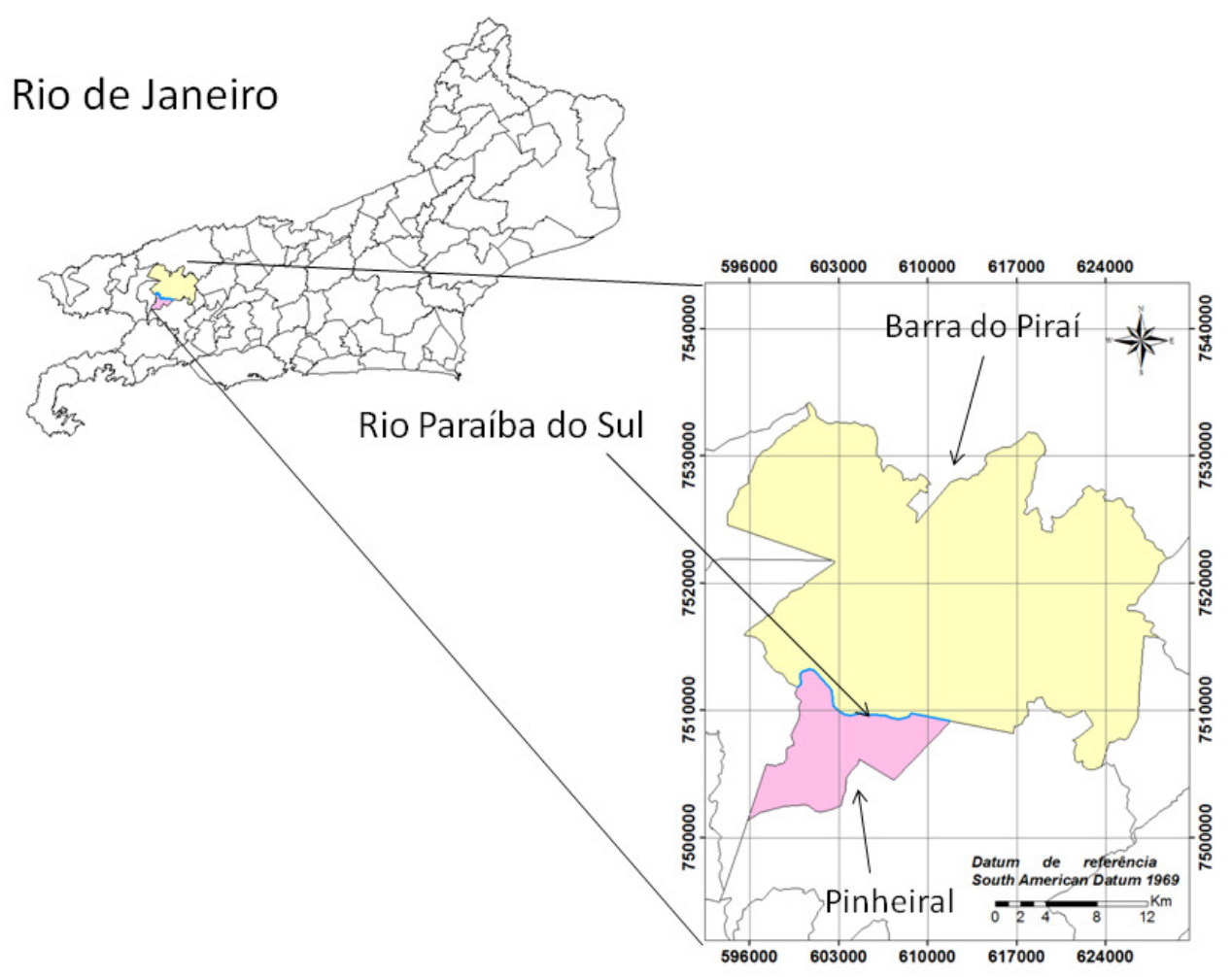

Figura 1. Localização da área de estudo.

\subsection{Mapeamento da APP e uso da terra}

Foram utilizadas imagens do Google Earth 5.0 (QuickBird, 05/07/2007), visualizadas numa distância de $5.000 \mathrm{~m}$ de altura. As imagens foram salvas no formato jpg e agrupadas em mosaico através do programa PanaVue 2.10. O mosaico foi georreferenciado no ArcGis 9.2, utilizando-se as coordenadas geográficas do próprio Google, que posteriormente foram transformadas em Datum WGS-84.

O rio Paraíba do Sul foi vetorizado no ArcGis, em formato shapefile, a partir do qual foi gerado um buffer de $100 \mathrm{~m}$ de largura para cada lado do rio e dentro das ilhas fluviais, delimitando, assim, a APP no trecho estudado. O uso da terra foi vetorizado, também em formato shapefile, utilizando-se escala 1:3.000. 
Foram calculadas as áreas (ha; \%) de cada tipo de uso da terra encontrado, classificado como:

- Floresta: área com mata ciliar natural ou plantada;

- Pastagem: área coberta por gramíneas, com ou sem atividade pecuária;

- Área urbana: ocupação por casas e edificações.

Foram delimitados os cursos d'água presentes na APP, como os trechos de rios afluentes e pequenos lagos adjacentes, porém não foram adicionados ao mapa devido ao pequeno tamanho da área obtida, o que dificulta sua visualização.

\section{Resultados e Discussão}

A área de preservação permanente do rio Paraíba do Sul, no trecho entre os municípios de Pinheiral e Barra do Piraí, compreendeu aproximadamente 305 ha. O uso da terra predominante foi a pastagem, cobrindo cerca de 54\% dessa área (Figura 2 e Tabela 1). A mata ciliar representou cerca $40 \%$ da APP. O restante da área encontrou-se ocupado por edificações, com exceção das ilhas fluviais, onde não foi encontrado esse tipo de ocupação. A pastagem também foi predominante nas ilhas fluviais. A área ocupada por cursos d'água adjacentes representou apenas 0,7 ha $(0,2 \%)$, porém foi retirada do mapa de uso da terra pela dificuldade na sua visualização.

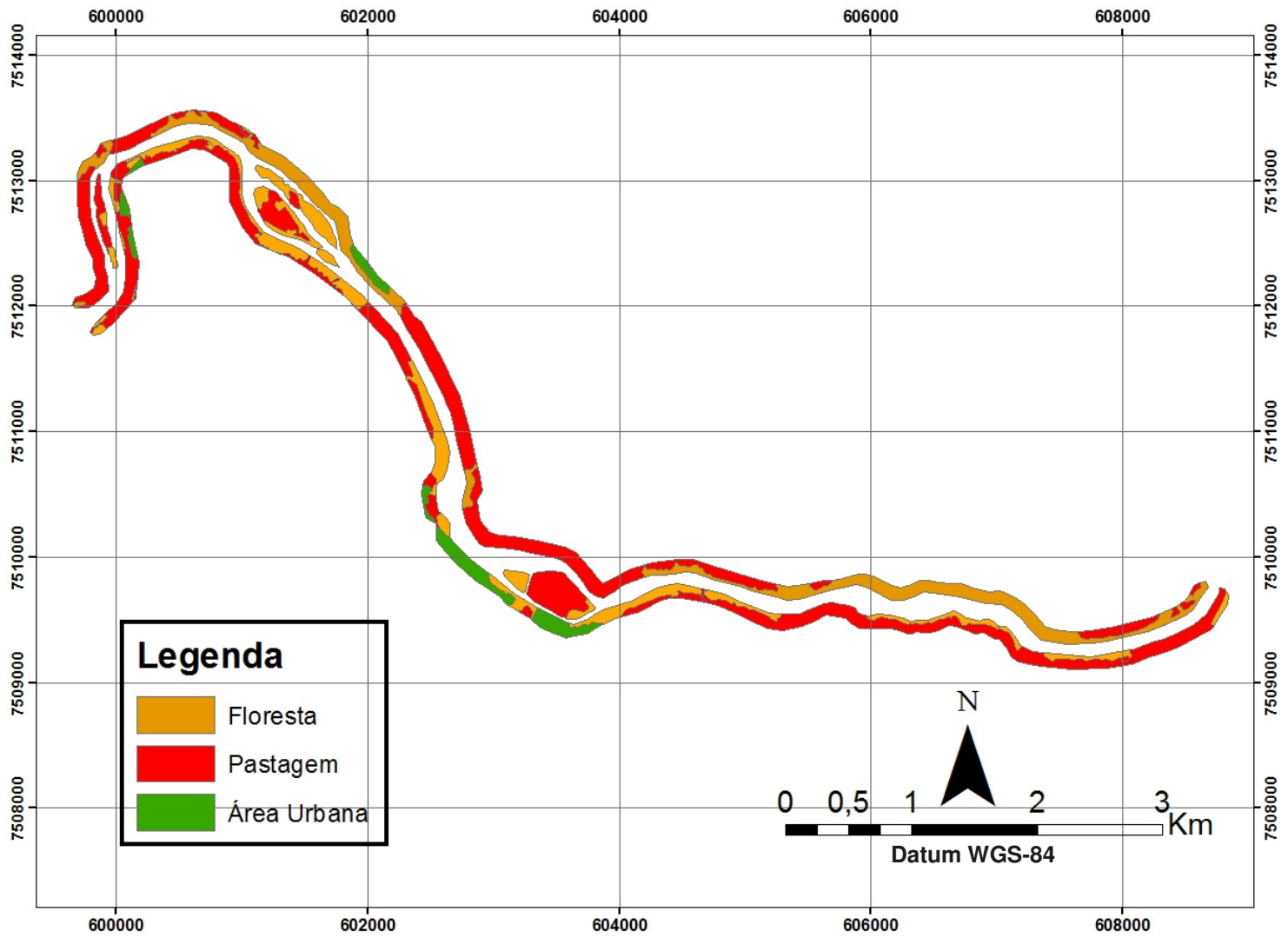

Figura 2. Uso da terra na APP do rio Paraíba do Sul, trecho entre Pinheiral e Barra do Piraí, RJ 
Tabela 1. Uso da terra na APP do rio Paraíba do Sul, no trecho entre os municípios de Pinheiral e Barra do Piraí, RJ

\begin{tabular}{|l|cc|cc|cc|cc|}
\hline \multirow{2}{*}{ Uso da Terra } & \multicolumn{2}{|c|}{ Barra do Piraí } & \multicolumn{2}{c|}{ Pinheiral } & \multicolumn{2}{c|}{ Ilhas fluviais } & \multicolumn{2}{c|}{ Total } \\
\cline { 2 - 10 } & ha & $\%$ & ha & $\%$ & ha & $\%$ & ha & $\%$ \\
\hline Floresta & 59,9 & 45,0 & 44,2 & 33,1 & 17,4 & 45,3 & 121,6 & 39,8 \\
Pastagem & 70,1 & 52,6 & 73,3 & 54,9 & 21,1 & 54,7 & 164,5 & 53,9 \\
Área urbana & 3,0 & 2,2 & 15,5 & 11,6 & - & - & 18,5 & 6,1 \\
\hline Total $^{*}$ & 133,2 & 100 & 133,5 & 100 & 38,5 & 100 & 305,3 & 100 \\
\hline
\end{tabular}

* Foi adicionado ao total a área referente a cursos d'água adjacentes.

O município de Barra do Piraí apresentou uma maior quantidade de mata ciliar em relação à Pinheiral, o que provavelmente se deve ao fato de que o centro urbano de Barra do Piraí se encontra mais afastado da área de estudo. A urbanização às margens de cursos d'água causam mais impacto no ambiente em comparação com a cobertura por pastagem, pois a pavimentação de ruas e as edificações impedem a infiltração de água no solo, prejudicando o abastecimento do lençol freático, além de favorecer processos erosivos nas margens causando o assoreamento.

Aproximadamente 94\% da APP apresentou algum tipo de cobertura vegetal (arbórea ou gramínea). Os valores encontrados nesse trecho do rio Paraíba do Sul são elevados quando comparados a outros estudos semelhantes sobre vegetação em APP's. No levantamento de uso da terra na APP do rio Guandu, RJ, realizado por Salamene (2007), apenas 11,6\% da APP do rio estava coberta por formações florestais. Ferreira e Dias (2004) encontraram um valor ainda mais inferior, com 5,7\% da área de mata ciliar que deveria existir, de acordo com a legislação vigente, no ribeirão São Bartolomeu, em Viçosa, MG.

\section{Conclusões}

Apesar de apenas 40\% da APP do rio Paraíba do Sul estar de acordo com a legislação, os valores encontrados foram elevados em comparação com outros estudos. Entretanto, não podemos extrapolar esses valores para todo o rio, pois o trecho estudado corresponde apenas à cerca de $1 \%$ de sua extensão total. Levantamentos de uso da terra em áreas estratégicas do rio poderão fornecer informações importantes para o planejamento adequado da ocupação do solo na APP, contribuindo para melhoria das suas condições ambientais.

\section{Referências}

Brasil. Lei n⿳ 4.771 de 15/09/1965. Institui o Código Florestal brasileiro.

Couto, J. L. V. Balanço hídrico da bacia do rio Paraíba do Sul com auxílio do geoprocessamento. Floresta e Ambiente, v. 5, n. 1, p.130-134, 1998.

Ferreira, D. A. C.; Dias, H. C. T. Situação atual da mata ciliar do Ribeirão São Bartolomeu em Viçosa, MG. Revista Árvore, v. 28, n. 4, p. 617-623, 2004.

INEA - Instituto Estadual do Ambiente, Governo do Estado do Rio de Janeiro. Rio Paraíba do Sul. Disponível em: <http://www.feema.rj.gov.br/bacia-rio-paraiba-sul.asp?cat=75>. Acesso em: 30 set. 2009.

Lima, W. P.; Zakia, M. J. B. Hidrologia de matas ciliares. In: Rodrigues, R. R.; Leitão-Filho, H. F. (Ed.). Matas ciliares: conservação e recuperação. São Paulo: Edusp/ Fapesp, 2a ed., 2004. 320 p.

Martins, S. V. Recuperação de matas ciliares. Viçosa, MG: Aprenda Fácil, 2001. 143 p.

Salamene, S. Estratificação e caracterização ambiental da Área de Preservação Permanente do rio Guandu, RJ. 2007. 67 p. Dissertação (Mestrado em Ciências Ambientais e Florestais) - Instituto de Florestas, Universidade Federal Rural do Rio de Janeiro, Seropédica, RJ. 2007. 
Anais II Seminário de Recursos Hídricos da Bacia Hidrográfica do Paraíba do Sul: Recuperação de Áreas Degradadas, Serviços Ambientais e Sustentabilidade, Taubaté, Brasil, 09-11 dezembro 2009, IPABHi, p. 379-384.

(doi:10.4136/serhidro.49)

Salvador, J. L. G. Comportamento de espécies florestais nativas em áreas de depleção de reservatórios. IPEF, n. 33 , p.73-78, 1986 